Jound of the Noreen themicel Society

2002. $[\theta] .+6 ., 0 \% 3$

Printed in the Republic of Korsa

\author{
폴리톨루이딘을 이용한 발광소자 연구 \\ 朴洙範 ${ }^{*} \cdot$ 李成柱 ${ }^{\dagger} \cdot$ 金容綠 \\ 수원내학피, 자연과학대학 화학-가 \\ 즈나트텍. NKIC' \\ 언세내 이롸내학 화학과 \\ (2002. 2. 18 십수)
}

\title{
Light Emitting Diodes based on Poly-o-toluidine
}

\author{
Soo Beom Park*, Sung Joo Lee ${ }^{\dagger}$, Yong Rok Kim*, and Eun Ok Kim

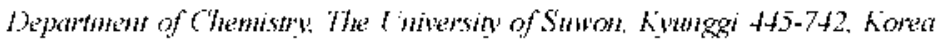

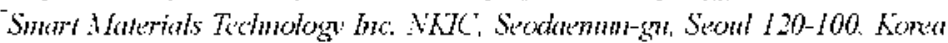

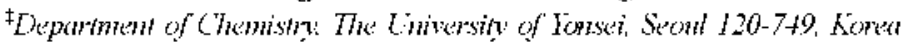 \\ (Received liebruary 18. 200002)
}

요 약. 폴러이닐런에 전자죽게기 $\left(-\mathrm{ClI}_{k}\right)$ 롤 치환하여 전자혀과 (electronic eflect)와 입체 장애호과(steric

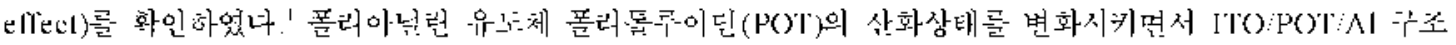
의 유기받광소사를 제삭하여 PL. I-V 특성 및 천기발광 특성은 확인하었다. 발광소사의 구동선압은 $9 \cdot 14 \mathrm{~V}$ 이었다.

주제어: 폰러돌쿡이던, 적계박광 적류-적압 특성, 광박광

\begin{abstract}
Poly- $\theta$-toluidine (POT) was chemically and electrochemically synthesized tor the study of electronic and steric eliect of melhyl substituents. The turn-on voltage of organic light emitling diode (O).FI) wats 9. $14 \mathrm{~V}$. ITO POT: $\Lambda$ I structured (OI, I:] were labricated with various oxidation states of POI. PI, I-V characteristics and FI. spectra were investigaled.
\end{abstract}

Keywords: Polytoluidinc. Electroluminescence. I-V. Photolumineseence

\section{서 론}

유기 1iJ, 밝광 데카니즘은 밝광홍으로 정공과 적자가

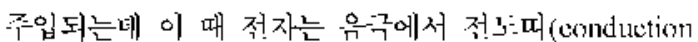
band)로, 정공은 양극에서 뷘자가띠(valence band)로 주 주

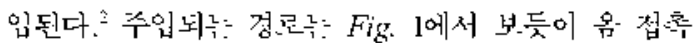
(olmic contact). 열이온 방출(thermionic emission). - 른 러고 터넢렁(tumncling) 등이 있다.?- 쭈입된 천자와 청 공은 각각 윾성폴라론(negalive polaron)화 양성폴라론 (positive polaron)이라는 우신잔자를 형성한다. 이 운신자 꽇이 체결합(recombination)에 의해 박광을 하는 것이
다. 본 연구의 뚜요 관침은 poly-o-toluidine(POT) ${ }^{6.8 ㅇ ㅢ ~}$ 산화상태를 변화시켜가며 PL 측침 및 유기 LED 소차 를 제직하여 그 툭섹을 알아보그 유ㄱㅣㅣ발광 물잘로쎠의 가능성을 알이보기 위합이나."

$\mathrm{PO}$ ()I는 폴러이닐런롸 따찬가지호 여러 가지 산화상태 를 갖는:다. 포 줌에서 특히 완천환원형(POT-LEB)이 발 광을 하는: 것으로 앍려져 있다. 따라서 POT-LEB와 POT-EB를 여러 가지 비율론 홯합하여 발광불진론 사 옹하였고 ITO를 양극 슥 정공주입 전:극으로. $\mathrm{A} 1$ 을 음 극 슥 전자중입 적극으로 한 충 구로의 소자를 제자하 여 I-V 특성 닟 전기밮광 특성을 확인하었나 


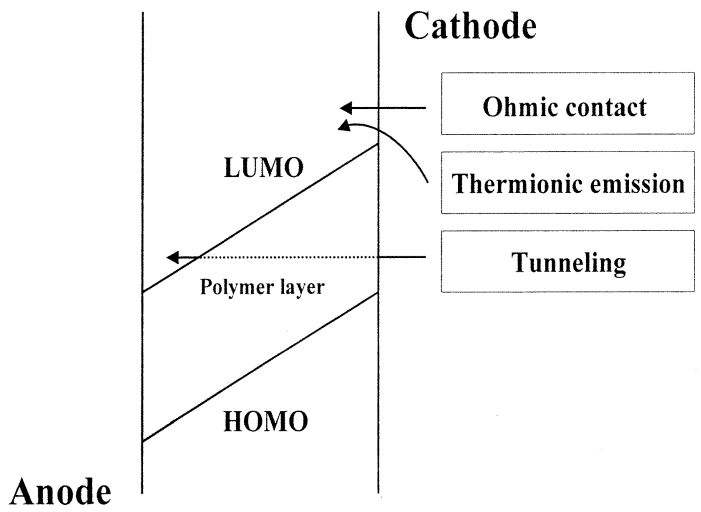

Fig. 1. Schematic tepresentation of cartict itjection.

\section{실 험}

\section{PI, 촉정}

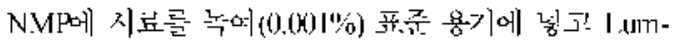
inescence spectrometer('Jerkin Elmer LB-50B 1 르 Pulse화 된 Xinon discharge lamp에서 $340 \mathrm{~nm}$ 의 빛을 여기광 원으론 사용하여 륵청하였다. 추사속도는 $1500 \mathrm{~nm} / \mathrm{min}$ 이었다.

\section{소자 제작}

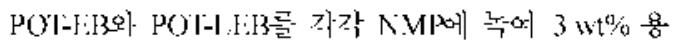
액으로 민들어 ITO기판 위에 스편코코힝 한 고분자뗜을 바녁으로 향하세 한 후 진공 쳅버를 $6 \times 10^{-6}$ torr아지 갑 압하였다. 약 10 18A에서 $\mathrm{Al}$ 을 확산시켜 선극을 증착

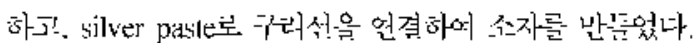

\section{I-V 촉정}

밝광소자의 전위차(V)와 전류의 세기(I)를 독립적으로 측첨하는: 사단사 식.류법(Four-probe d.c. method)은 이용하었다. 와 V를 Source Measunment Unit(KEITHLEY 236)으로 측싱하였다.

\section{EL, 촉정}

Fluovexence Spectrophotometer(litichi F-1500)아 IX: power supply(I)RP-505I) 를 시용하여 밪광톡성을 화 인하었다. 5.4 V론 ITO선극에 양전합. Al선극에 을선압 은 걸어뚜었고. 겁출기의 쭈사 속도눅: $1500 \mathrm{~nm} / \mathrm{min}$ 이 었다.

\section{결과 및 고찰}

Fig. 2에서 $350 \mathrm{~nm} \sim 650 \mathrm{~nm}$ 에 설쳐서 나타나는: PL

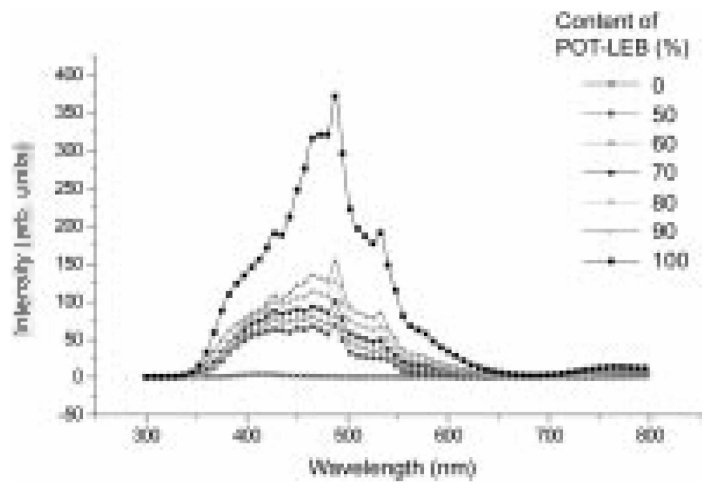

Fig. 2. P]. spectra of POI for the content of POI-[.F.B it clilorotorm.

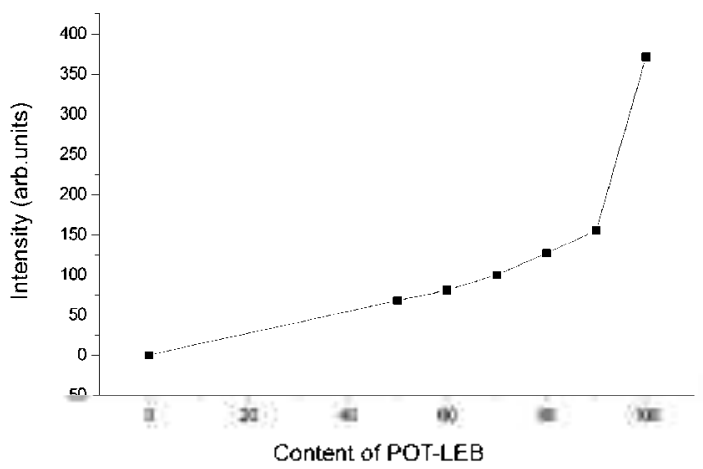

figr. 3. Conelation diagram of PL intensity vs. the contents

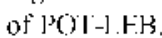

피크는 JPOT-LEB 핚챵이 준어들수록 I'L세기도 갑소하. 는 경향을 뜨고 잇나. 대체적으로 POIIIIIB 양에 따라 피커세기가 일정하게 각소하지난. POI-I,IIB가 100\%에 서 $90 \%$ 호 갆-스할 때 급격힌 세기 갂-소가 있는 것을 알 수 있다. 이것음 중간산화형의 뷔는형고리가 자체소광 (sclt-quenching). 자체 홉수(sclf-absorption) 뜬는: 외부신 환의 겅우 에니지가 용매분자론 천이하는 것과 같은 비 복사 완화(nonradiative relaxation) 둠에 의해서 발강을 낭해하거나 또는 발광을 홓숫해서 나타나는 현 상이나. lig. 3에 $487 \mathrm{~nm}$ 근체의 $\lambda_{\text {Itaix }}$ 세기와 POT-I.1:13 합량에 마른 관계를 나타네었다. $\lambda_{\text {a․ }}$ 는 산화상태에 관계없이 각삭 $485 \mathrm{~nm}$ 와 $490 \mathrm{~nm}$ 사이에서 일싱하게 나타닜다.

Source Mcasurement linit의 +극에 ITO선극을 -극 에 $\Lambda$ 전ㄷㄱㄱ을 언결한 후 적압을 길어 촉정한 전류를 $\mathrm{hg}$. 4에 나타내었나. POT-1.113난을 사옹하여 제자한 소자

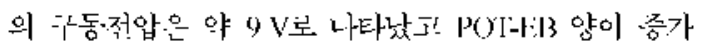
할수록 구동신압도 짐심 증가하여 POT-EB만옳 사용한 


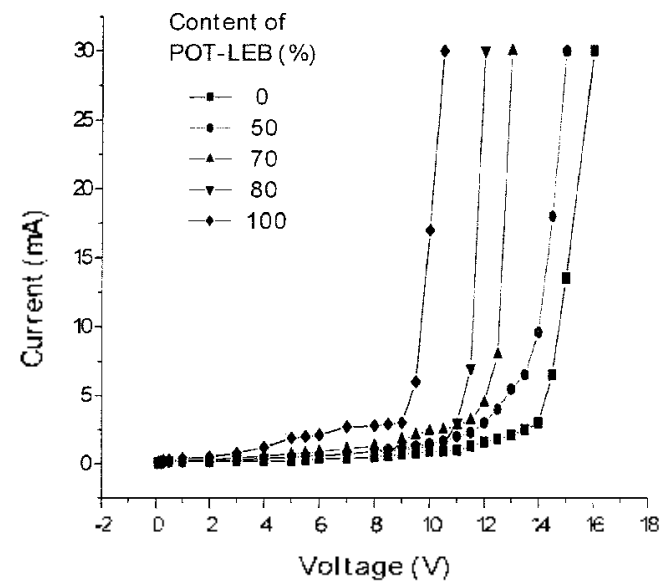

Fig. 4. I-V characteristics of POT for the contents of POTI,I:B.
소자는 약 $14 \mathrm{~V}$ 로 나타났다. POI-1 diB 양이 $90{ }^{*}{ }^{\prime}$ 인 것 과 $60^{\circ} \%$ 인 것의 $1-V$ 는 소자가 타버볐나. 제직독 소자에 전원 $14 \mathrm{~V}$ 롤 가해주거 $1 \mathrm{i} I$ 을 촉정한 결과롤 $/ \mathrm{ig}$. 5 에 나타내었다. $\mathrm{EL}$ 은 노두 $300.800 \mathrm{n} 1 \mathrm{~m}$ 영억에 걸쳐서 나 타났고 POT-EB 함량이 증가할수록 단파장 이동(blue shift)을 보었다. POT-LEB 향이 $80^{\circ}{ }_{0}$ 와 $50^{\circ}$ 인 소사는 타면서 닟을 밮해 나론 형태의 스펙트럳을 나타내었다 /ig. 6에 POI-I,III3 합량에 따른 $\lambda_{\text {taxaㅇ }}$ 의 변화를 나타내

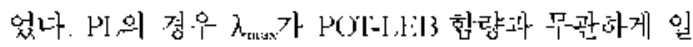
성한뎨 반하여 EL은 $\lambda_{\max }$ 의 견화카 있었다. PL과 다르 제 EL에서 POT-LEB 핚향에 마른 세기변화를 나타네 지 않은 것은. EL 축싱 시 소사가 매번 건출기의 동일 한 위치에 고정되어야 하는데 poner supply로 전윈-을 공급하므로 위치를 정화히 힐치시킬 숭 없기 때문이나
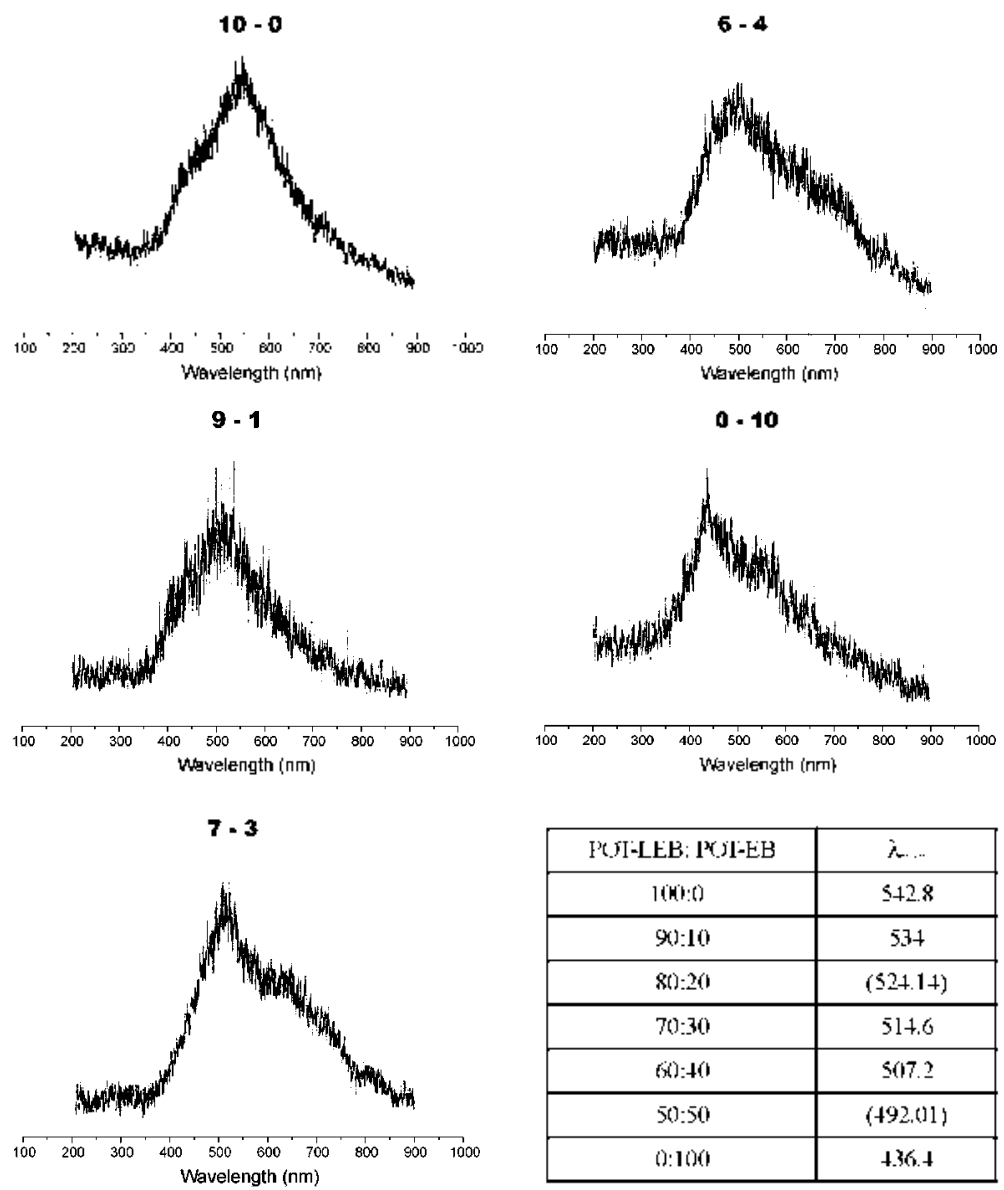

\begin{tabular}{|c|c|}
\hline PUI-LEB: P(SI-EB & $\lambda \ldots$ \\
\hline 1000 & $\$+2.8$ \\
\hline 9010 & 534 \\
\hline $800: 20$ & $(\S 2+14)$ \\
\hline $70: 30$ & 514.6 \\
\hline 60$): 40$ & 5017.2 \\
\hline $50: 50$ & $(492,011)$ \\
\hline $0: 100$ & 4.36 .4 \\
\hline
\end{tabular}

Fig. 5. EL spectra of POT for the contents of POT-LEB. 


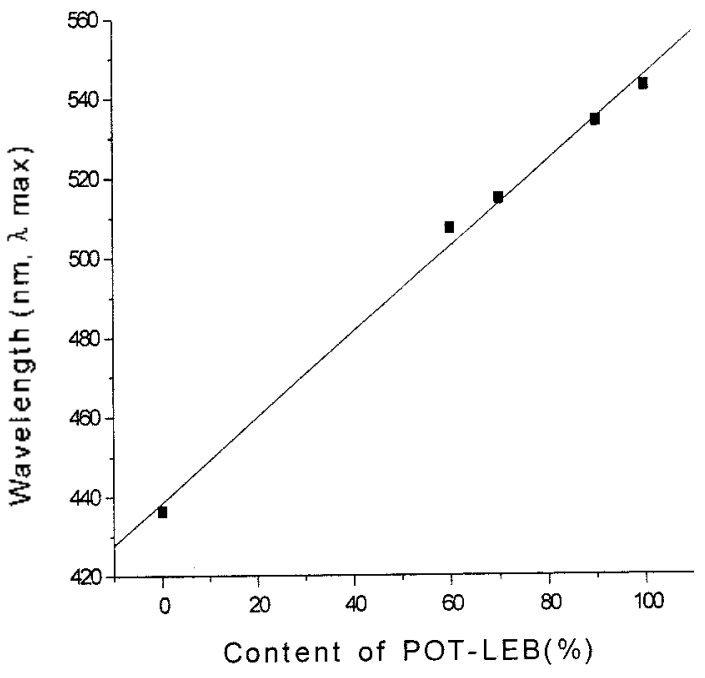

Fig. 6. Conelation diagram for the contents of POl-LEB and $\lambda_{\text {max }}$ of $5: I$, spectra.

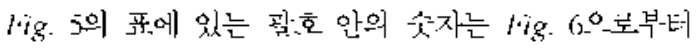
예상되는 $\lambda_{\text {max }}$ 값이나.

\section{결 론}

PL 측정견과 LEB 함낭이 증가할수록 $\mathrm{PL}$ 세기가 칙 석적으로 증가하므로 환원혐(벤젠형 피러) 에서난 발광 하는 것을 에측할 수 있었나. I10 J, I:13:A1 구로로 제지. 됙! 소자는 $9 \mathrm{~V} \cdot 14 \mathrm{~V}$ 의 작동전압을 보었 5 ‥ $30 \% \mathrm{~nm}$ 에서
$8011 \mathrm{~mm}$ 까지 가시광신 영영의 white radialion(낵섹광) 이 있음을 화인하었나. 밪광층에 [,1:13반 사용한 소자가 가장 쫗은 PL과 EL 특성은 나타네었다.

소사 구동전압은 $9 \mathrm{~V} \cdot 14 \mathrm{~V}$ 아지 나타났는뎨 이것은 $\mathrm{EL}$ 측성시 나타난 탄원힝 갑소에 마른 단파장이동 견 과아 일치했나. PI, 콕정시 산화상태 변화에 따론 $\lambda_{\text {nnn }}$ 이동은 없었고 환윈혐 감 소에 따금 세기 갂 소가 관찰되 었다. 폰리돌곡이딘은 전기 밪광물질로 완전환윈형이 가 장 적합핚은 확인하있다.

\section{인 용 문 헌}

1. Park. S. B.: Lee. S. J.: Kim. E. O. Synthesis and electrochemical characterization of loly-o-toluidine in press.

2. Parker. 1. D. J. Appl. Phws. 1994. 75. 1657.

3. Blom. I. W. M.: de Jong. M. J. M.: Vleggaar. I. I. M. .tppl. Phos. Lett. 1996. 69. 23.

4. Campbell, I. II.; Darids. P. S.: Smith. D. I.: Barasthox. N. N.: Ferratis, J. P. Ippl. Fhys. lett 1998. 72, 1863. 5. Crone, B. K.: Campbell. I. II.; Darids. P. S.: Smith. D J. ilppl Fhus tett. 1998, 73, 21

6. MacDiarmid. A. G.: F.pstein. A. I. J. (Them. Six. Faradat? Fise. 1989. 88.317

7. I.eclere. M.: Apprano. G. D.: 7otti. G. Synth. Wet 1993. $55,1527$.

8. Manohar. S. K.: MacDiarmid. A. G.: Cromack. K. R.:

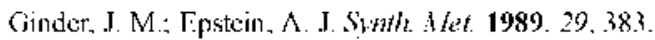

9. Kin, F. O.: Park. S. B.: Iloo, S.: I Lec. S. I. J. Kin Chem. Soc. 2001, 45,2 